\title{
Association of P wave Dispersion with Angiographic Severity in Patients with Chronic Stable Angina
}

\author{
SYED NAZMUL ISLAM ${ }^{1}$, SYED ALI AHSAN ${ }^{1}$, MANZOOR MAHMOOD ${ }^{1}$, DIPAL KRISHNAADHIKARY ${ }^{1}$, \\ KHURSHED AHMED ${ }^{1}$, SYEDA NIGER SULTANA ${ }^{2}$, JANNATUN NAHAR ${ }^{1}$, KAMRUZZAMAN SIDDIKI ${ }^{1}$, \\ MOHAMED MAUSOOL SIRAJ ${ }^{1}$, ABU TAHER MOHAMMED ZUBAIR RAHMAN ${ }^{1}$, ADNAN BASHAR ${ }^{1}$, \\ CHAUDHURY MESHKAT AHMED ${ }^{1}$, SAJAL KRISHNA BANERJEE. ${ }^{1}$
}

${ }^{1}$ Department of Cardiology, Bangabandhu Sheikh Mujib Medical University (BSMMU), Dhaka, ${ }^{2}$ Department of Microbiology, Dhaka Medical College, Dhaka

Address of Correspondence: Dr. Syed Nazmul Islam, Resident, Department of Cardiology, BSMMU, Dhaka, E-mail: dr.sni.47@gmail.com

\begin{abstract}
:
Background:Stable angina forms a significant proportion of coronary artery disease. Newer non-invasive modalities with good predictive values like CT coronary angiography and myocardial perfusion imaging are available, they are not feasible for widespread use. In this scenario, we can use the ECG parameter (P wave dispersion) as a non-invasive, efficient and cost-effective tool for diagnosing coronary artery stenosis in chronic stable angina.

Objective: To find out the association between $P$ wave dispersion in electrocardiogram and angiographic findings by coronary angiogram in patients with chronic stable angina.

Methods: This cross sectional study was conducted at the Department of Cardiology, Bangabandhu Sheikh Mujib Medical University, Dhaka from July 2018 to June 2019.Patients with chronic stable angina who were undergoing invasive coronary angiography was included in this study. A total of 45 patients were included in the study. Immediately after admission, standard 12 lead ECG was recorded at a $50 \mathrm{~mm} / \mathrm{s}$ paper speed and a gain of $10 \mathrm{~mm} / \mathrm{mV}$. P wave dispersion are calculated from the standard ECG during sinus rhythm in any of the 12 ECG leads. Finally, all the enrolled patients underwent invasive evaluation by coronary angiography. The severity of CAD was assessed by Gensini score.

Results:The mean PD was 23.3 \pm 8.1 millisecond in patients without CAD, 37.1 \pm 7.6 millisecond in single vessel disease, 45.3 \pm 9.1 millisecond in double vessel disease and $45.9 \pm 9.4$ millisecond in triple vessel disease, which were statistically significant $(p<0.05)$ among four groups. There was a significant correlation of PD (P wave dispersion) with Gensini score $(r=0.631 ; p=0.001)$.

Conclusion: This study demonstrates that there is a significant association of PD (P wave dispersion) with the severity of coronary artery disease in patients with chronic stable angina.
\end{abstract}

Key Words: Chronic stable angina; Coronary artery disease; Electrocardiogram; Gensini score; P wave dispersion.

University Heart Journal 2021; 17(2): 81-85

Introduction:

Cardiovascular diseases (CVDs) are the most common cause of premature death worldwide, accounting for 17.9 million deaths per year. ${ }^{1}$ Despite decreasing mortality trends of coronary artery disease (CAD) in many developed countries, increasing number is noticed in developing countries. ${ }^{2}$ The prevalence of CAD in a Bangladeshi rural population was $4.5 \%$. Compared with the female $(3.5 \%)$ the male participants had a significantly higher prevalenceof CAD $(6.0 \%)$. The younger people had a similar risk as the aged people. ${ }^{3}$ The prevalence of CAD in working professionals in Dhaka was $19.6 \%$ as evident in a study by Ahsan et al. (2009). ${ }^{4}$

The clinical presentations of coronary artery disease include silent ischemia, stable angina pectoris, acute coronary syndrome, heart failure, and sudden death. ${ }^{5}$ So 
the ability to predict the presence of significant coronary stenosis can help to decrease morbidity and mortality due to IHD. Electrocardiogram (ECG) is a very early noninvasive marker to predict CAD. Electrocardiography is the most immediately accessible and widely used diagnostic tool. It has proven its efficacy in diagnosis, therapeutic and prognosis of ACS patients. There is a need to determine subgroups of patients having anatomically or functionally severe coronary obstruction based on standard 12-lead ECG interpretation. ${ }^{6}$

$\mathrm{P}$ wave dispersion $(\mathrm{PD})$ is defined as the difference between the maximum $\left(\mathrm{P}_{\max }\right)$ and the minimum $\mathrm{P}$ wave duration $\left(\mathrm{P}_{\min }\right)$. $\mathrm{P}$ wave dispersion (PD) on standard ECG is a noninvasive markers of in homogeneous and discontinuous propagation of sinus impulses through the atrial wall ${ }^{7}$ (Dilaveris et al., 1998).The normal value of $\mathrm{PD}$ is $29 \pm 9 \mathrm{~ms} .{ }^{8} \mathrm{P}$ wave dispersion is a measure of heterogeneity of atrial refractoriness and an increase in PD shows the intra-atrial and inter-atrial nonuniform conduction ${ }^{9}$ (Yazici et al., 2007). P wave parameters have been studied in some cardiac conditions such as hypertension, paroxysmal AF, valvular heart disease, dilated cardiomyopathy and acute myocardial infarction and coronary angioplasty ${ }^{10,11}$ (Aytemir et al., 2000; Ozmen et al., 2001).

Although it has been demonstrated that PD is increased during the above-mentioned conditions, the effect of stable coronary artery disease (CAD) on the $\mathrm{P}$ wave dispersion and relation between $P$ wave parameters and severity of CAD have not yet been well established in our country. So it is high time to conduct a study in our setting to see the association of $\mathrm{P}$ wave dispersion with severity of $\mathrm{CAD}$ in patients with chronic stable angina.

\section{Materials and Methods:}

Study population: This cross sectional study was carried out in the Department of Cardiology, University Cardiac Center, Bangabandhu Sheikh Mujib Medical University, Dhaka from July 2018 to June 2019. Patients with stable angina who underwent coronary angiography for detection of coronary artery disease were included in this study. A total of 45 patients were enrolled in the study. Patients with acute coronary syndrome, angina at rest, valvular heart disease, any arrhythmia, hypertension, congenital heart disease, lung diseases, electrolyte abnormality, heart failure, old myocardial infarction, percutaneous coronary intervention, coronary artery bypass graft were excluded.

Methodology: The eligible patients were explained about the study, written informed consent was taken. Detailed medical history and physical examination were done.
Immediately after admission, standard 12 lead ECG was recorded at a $50 \mathrm{~mm} / \mathrm{s}$ paper speed and a gain of $10 \mathrm{~mm} / \mathrm{mV}$ in the supine position. Maximum and minimum $\mathrm{P}$ wave durations are calculated from the standard ECG during sinus rhythm. P wave dispersion (PD) is derived by subtracting the minimum $P$ wave duration from the maximum in any of the 12 ECG leads. Manual measurement was done by handheld calipers and accompanied by the use of magnification. Transthoracic echocardiography was done before coronary angiography. Other laboratory investigations such as CBC, Random blood glucose level, HbA1c, Fasting lipid profile were collected. Finally, all the enrolled patients underwent invasive evaluation by coronary angiography. Diagnostic coronary angiography was performed by expert interventional cardiologist. The extent and severity of coronary artery disease (CAD) was assessed by vessel score and Gensini score. Separate data collection sheet was used for each subject with maintaining confidentiality.

Statistical analysis: Statistical analyses were carried out by using the Statistical Package for Social Sciences (SPSS) version 23.0 for Windows Software. Continuous data were expressed as mean \pm standard deviation (SD) and categorical data were expressed as frequency and percentages. Mean and standard deviation were computed for quantitative variables and was analyzed by ANOVA test. The association of ECG (PD) with the Gensini score was done by Pearson's correlation coefficient test. P values $<0.05$ was considered as statistically significant.

\section{Results:}

In the study period, total 45 patients were enrolled in the study according to inclusion and exclusion criteria. Detailed analysis of patients was done.

The mean age was found $54.5 \pm 10.4$ years and the majority $(40.0 \%)$ of the patients belonged to age $50-60$ years. Table I shows age distribution of the study population.

Table-I

Age distribution of the study population $(n=45)$

\begin{tabular}{lcc}
\hline Age (years) & Frequency & Percentage \\
\hline$\leq 40$ & 4 & 8.9 \\
$41-50$ & 13 & 28.9 \\
$50-60$ & 18 & 40.0 \\
$61-70$ & 7 & 15.6 \\
$>70$ & 3 & 6.7 \\
Mean \pm SD & 54.5 & \pm 10.4 \\
Range & 32 & -78 \\
\hline
\end{tabular}

$\mathrm{n}=$ Number of study population, $\mathrm{SD}=$ Standard deviation

Almost two-thirds (64.4\%) patients were male and 16(35.6\%) were female. The male-female ratio was 1.8:1. Figure 1 shows the sex distribution of the study population. 


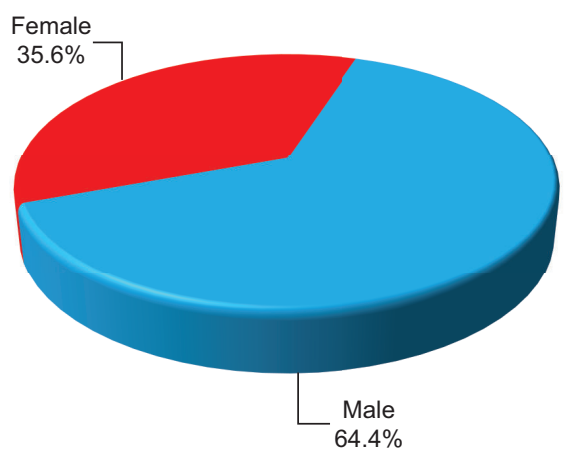

Fig.-1: Pie chart shows the sex distribution of the study population $(n=45)$

$\mathrm{n}=$ Number of study population

The mean $\mathrm{P}_{\max }$ was found $116.9 \pm 12.7 \mathrm{msec}$, the mean $\mathrm{P}_{\min }$ was found $75.1 \pm 8.7 \mathrm{msec}$ and the mean PD was found $41.3 \pm 11.6 \mathrm{msec}$. Table II shows the distribution of the study population according to $\mathrm{ECG}\left(\mathrm{P}_{\max }, \mathrm{P}_{\min }\right.$ and $\left.\mathrm{PD}\right)$.

Table-II

Distribution of the study population according to ECG $\left(P_{\max }, P_{\min }\right.$ and $\left.P D\right)(n=45)$

\begin{tabular}{lcc}
\hline ECG & Mean & \pm SD \\
\hline $\mathrm{P}_{\max }$ (Millisecond) & 116.9 & \pm 12.7 \\
Range & 80 & -140 \\
$\mathrm{P}_{\min }$ (Millisecond) & 75.1 & \pm 8.7 \\
Range & 60 & -80 \\
PD (Millisecond) & 41.3 & \pm 11.6 \\
Range & 20 & -60 \\
\hline
\end{tabular}

$\mathrm{n}=$ Number of study population, $\mathrm{SD}=$ Standard deviation, $\mathrm{P}_{\text {max }}=$ Maximum $\mathrm{P}$ wave duration, $\mathrm{P}_{\min }=$ Minimum $\mathrm{P}$ wave duration, $\mathrm{PD}=$ $\mathrm{P}$ wave dispersion.

More than half (51.1\%) of the patients were found to have positive ETT followed by 20(44.4\%) in conclusive, $1(2.2 \%)$ negative and $1(2.2 \%)$ equivocal ETT. Figure 2 shows the distribution of the study population according to ETT.

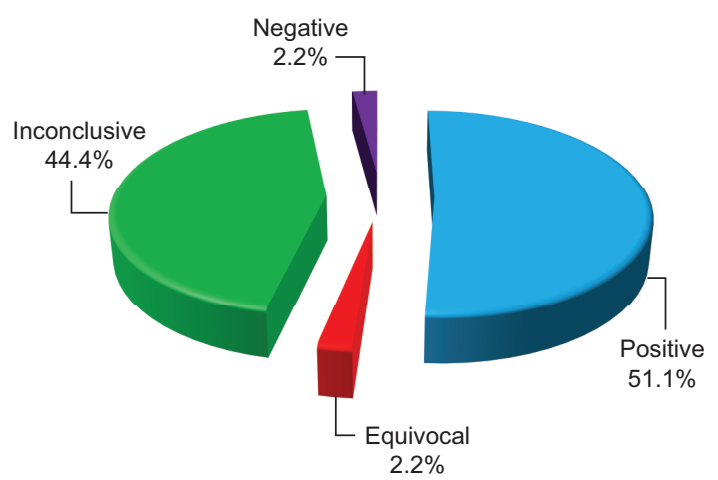

Fig.-2: Pie chart shows the ETT of the study population $(n=45)$

$\mathrm{n}=$ Number of study population, ETT $=$ Exercise tolerance test
Thirty-nine (86.7\%) patients had significant CAD $(\geq 70 \%$ lesion in any major coronary arteries or $\geq 50 \%$ lesion in left main artery) and $17(37.8 \%)$ had triple vessel disease. Table III shows the distribution of the study population according to Coronary Angiography.

\section{Table-III}

Distribution of the study population according to Coronary Angiography ( $n=45)$

\begin{tabular}{lcc}
\hline Coronary Angiography & Frequency & Percentage \\
\hline Significant CAD & & \\
$\quad$ Yes & 39 & 86.7 \\
$\quad$ No & 6 & 13.3 \\
Number of vessel involved & & \\
No CAD & 6 & 13.3 \\
Single vessel disease & 7 & 15.6 \\
Double vessel disease & 15 & 33.3 \\
Triple vessel disease & 17 & 37.8 \\
\hline
\end{tabular}

$\mathrm{n}=$ Number of study population, $\mathrm{CAD}=$ Coronary artery disease.

More than three fourth (75.6\%) patients had Gensini score $\geq 36$. Mean Gensini score was $45.7 \pm 27.4$ with range from 0.0 to 108.0 . Table IV shows the distribution of the study population according to Gensini score.

\section{Table IV}

Distribution of the study population according to Gensini score ( $n=45)$

\begin{tabular}{lcc}
\hline Gensini score & Frequency & Percentage \\
\hline$<36$ (absent or mild coronary & 11 & 24.4 \\
atherosclerosis) & & \\
$\geq 36$ (moderate to severe & 34 & 75.6 \\
coronary atherosclerosis) & & \\
Mean \pm SD & 45.7 & \pm 27.4 \\
Range & 0.0 & -108.0 \\
\hline
\end{tabular}

$\mathrm{n}=$ Number of study population, $\mathrm{SD}=$ Standard deviation.

The mean $\mathrm{P}_{\max }$ was $96.7 \pm 8.2 \mathrm{msec}$ in patients without coronary artery disease, $111.7 \pm 10.7 \mathrm{msec}$ in single vessel disease, $120.0 \pm 10.7 \mathrm{msec}$ in double vessel disease and $122.4 \pm 9.7 \mathrm{msec}$ in triple vessel disease. The mean PD was $23.3 \pm 8.1 \mathrm{msec}$ in patients without coronary artery disease, $37.1 \pm 7.6 \mathrm{msec}$ in single vessel disease, $45.3 \pm 9.1 \mathrm{msec}$ in double vessel disease and $45.9 \pm 9.4 \mathrm{msec}$ in triple vessel disease, which were statistically significant $(p<0.05)$ among four groups. Table $\mathrm{V}$ shows the association between vessel score and $\mathrm{ECG}\left(\mathrm{P}_{\max }, \mathrm{P}_{\min }\right.$ and $\left.\mathrm{PD}\right)$. 
Table-V

Association between vessel score and ECG $\left(P_{\max }, P_{\min }\right.$ and PD)

\begin{tabular}{lccccc}
\hline ECG & \multicolumn{4}{c}{ Vessel score } & P-value \\
\cline { 2 - 5 } & No CAD $(\mathrm{n}=6)$ & Single $(\mathrm{n}=7)$ & Double $(\mathrm{n}=15)$ & Triple $(\mathrm{n}=17)$ & \\
& Mean $\pm \mathrm{SD}$ & Mean \pm SD & Mean \pm SD & Mean $\pm \mathrm{SD}$ & \\
\hline $\mathrm{P}_{\max }$ (Millisecond) & $96.7 \pm 8.2$ & $111.4 \pm 10.7$ & $120.0 \pm 10.7$ & $122.4 \pm 9.7$ & $0.001^{\mathrm{s}}$ \\
Range & $80-100$ & $100-120$ & $100-140$ & $100-140$ & \\
$\mathrm{P}_{\text {min }}$ (Millisecond) & $73.3 \pm 10.3$ & $74.3 \pm 9.8$ & $73.3 \pm 9.8$ & $76.5 \pm 7.9$ & $0.772^{\text {ns }}$ \\
Range & $60-80$ & $60-80$ & $60-80$ & $60-80$ & \\
PD (Millisecond) & $23.3 \pm 8.1$ & $37.1 \pm 7.6$ & $45.3 \pm 9.1$ & $45.9 \pm 9.4$ & $0.001^{\mathrm{s}}$ \\
Range & $20-40$ & $20-40$ & $40-60$ & $40-60$ & \\
\hline
\end{tabular}

$\mathrm{n}=$ Number of study population, $\mathrm{SD}=$ Standard deviation, $\mathrm{ECG}=$ Electrocardiogram, $\mathrm{P}_{\max }=$ Maximum $\mathrm{P}$ wave duration, $\mathrm{P}_{\min }=\mathrm{Minimum} \mathrm{P}$ wave duration, $\mathrm{PD}=\mathrm{P}$ wave dispersion, $\mathrm{s}=$ significant, $\mathrm{ns}=$ not significant, $\mathrm{P}$-value reached from ANOVA test.

Pearson's correlation coefficient test shows that there is a significant correlation of PD (P wave dispersion) with Gensini score $(r=0.631 ; p=0.001)$. Figure 3 shows the correlation between PD (P wave dispersion) and Gensini score.

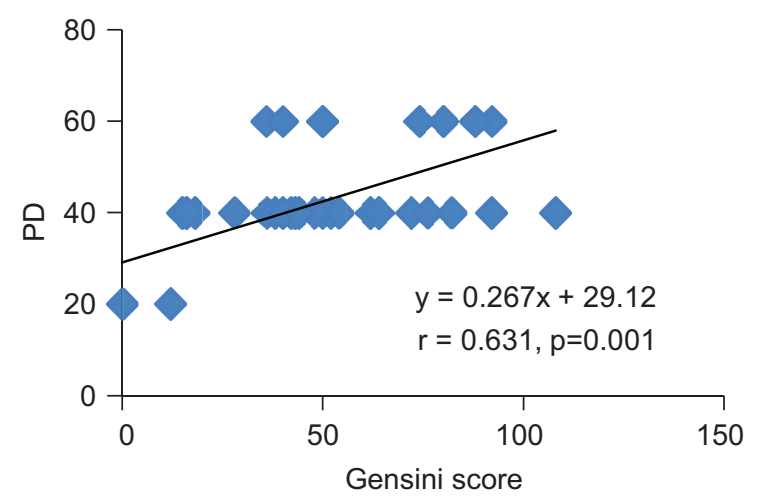

Fig.-3: Scatter diagram showing positive correlation ( $r=0.631 ; p=0.001)$ between $P D(P$ wave dispersion $)$ and Gensini score.

$\mathrm{PD}=\mathrm{P}$ wave dispersion, $\mathrm{r}=$ Pearson's correlation coefficient, P-value reached from Pearson's correlation coefficient test.

\section{Discussion:}

In this study, the mean age was $54.5 \pm 10.4$ years. Sahin et al. (2016) reported the average age of the patients $57.9 \pm 8.5$ years. ${ }^{12}$ Akin et al. (2014) also reported similar observations. ${ }^{13}$ This study showed that almost two-thirds $(64.4 \%)$ patients were male and the male-female ratio was 1.8:1. Sahin et al. (2016) reported sixty-two participants were female $(24.8 \%)$ while 188 participants were male $(75.2 \%)^{12}$
In the current study, we observed that the mean $\mathrm{P}_{\max }, \mathrm{P}_{\min }$ and $\mathrm{PD}$ value were almost similar to the study done by Akin et al. (2014). ${ }^{13}$

In this study, we observed that $39(86.7 \%)$ patients had significant CAD and 17(37.8\%) had triple vessel disease. Akin et al. (2014) also reported 60 patients had significant $\mathrm{CAD}^{13}$. Yilmaz and Demirbag (2005) reported that $11.9 \%$ of patients had triple vessel disease. ${ }^{14}$

In the current study, we observed that more than three fourth $(75.6 \%)$ patients had Gensini score $\geq 36$ (moderate to severe coronary atherosclerosis). Mean Gensini score was $45.7 \pm 27.4$ with range from 0.0 to 108.0 .

In the present study, we observed that mean $\mathrm{P}_{\max }$ value was gradually increasing from without CAD to triple vessel disease. The difference was statistically significant $(p<0.05)$ among four groups. Akin et al. (2014) also reported similar study results. ${ }^{13}$ We also observed that mean PD value was gradually increasing from without CAD to triple vessel disease. The difference was statistically significant $(p<0.05)$ among four groups. These findings were consistent with other studies (Yilmaz and Demirbag, 2005; Akin et al., 2014; Sahin et al., 2016). ${ }^{12,13,14}$ Ozmen et al. (2001) confirmed PD in patients with angioplasty induced myocardial ischemia. ${ }^{11}$

In this study, we observed that there was a significant correlation of PD (P wave dispersion) with Gensini score $(r=0.631 ; p=0.001)$. Similar observation was reported by Akin et al. (2014), they showed positive correlations between Gensini score and PD $(r=0.825, p<0.001)^{13}$. Yilmaz and Demirbag (2005) reported that PD was positively correlated with both the vessel and Gensini scores ( $\mathrm{r}=$ $0.465, \mathrm{P}<0.001$; and $\mathrm{r}=0.338, \mathrm{P}=0.005$, respectively). ${ }^{14}$ 
The findings of our study were consistent with the findings of previous studies though the study group was different. So, according to the results of this study, patients with higher PD values have more severe CAD. Therefore, we can use this ECG parameter for assessment of the severity of CAD in patients with chronic stable angina.

\section{Limitations}

There are some facts to be considered which might affect the results. The sample size was small in number and it was conducted in a single center. The sampling method was not random rather purposive, so there is a risk of selection bias.Coronary angiography was assessed by visual observation; intravascular ultrasonography was not used, so there was every chance of inter observer variation.

\section{Conclusion:}

This study reveals that there is a significant association of PD ( $\mathrm{P}$ wave dispersion) with severity of coronary artery disease in patients with chronic stable angina. Higher $\mathrm{P}$ wave dispersion is associated with a more severe form of coronary artery disease. So $\mathrm{P}$ wave dispersion has significant value for assessment of presence and the severity of coronary artery disease in patients with chronic stable angina.

\section{References}

1. Roth GA, Johnson C, Abajobir A, Abd-Allah F, Abera SF, Abyu G, Ahmed M, Aksut B, Alam T, Alam K, Alla F. Global, regional, and national burden of cardiovascular diseases for 10 causes, 1990 to 2015. Journal of the American College of Cardiology. 2017;70(1):1-25.

2. Bhatnagar P, Wickramasinghe K, Williams J, Rayner M, Townsend N. The epidemiology of cardiovascular disease in the UK 2014. Heart. 2015;101(15):1182-89.

3. Banerjee SK, Ahmed CM, Rhaman MM, Chowdhury MM, Sayeed MA. Coronary artery disease in a rural population of Bangladesh: is dyslipidemia or adiposity a significant risk ?. IMC Journal of Medical Science. 2017 ;11(2):61-69.

4. Ahsan SA, Haque KS, Salman M, Bari AS, Nahar H, Ahmed MK, Hoque MH, Rahman MM, Hossain MA, Sultan MA. Detection of ischaemic heart disease with risk factors in different categories of employees of University Grants Commission. University Heart Journal. 2009;5(1):20-23.
5. Hamm CW, Bassand JP, Agewall S, Bax J, Boersma E, Bueno H, Caso P, Dudek D, Gielen S, Huber K, Ohman M. Guía de prácticaclínica de la ESC para el manejo del síndromecoronarioagudoenpacientes sin elevaciónpersistente del segmento ST. Revista Española de Cardiología. 2012;65(2):173.

6. Hennings JR, Fesmire FM. A new electrocardiographic criteria for emergent reperfusion therapy. The American journal of emergency medicine. 2012;30(6):994-1000.

7. Dilaveris PE, Gialafos EJ, Sideris SK, Theopistou AM, Andrikopoulos GK, Kyriakidis M, Gialafos JE, Toutouzas PK. Simple electrocardiographic markers for the prediction of paroxysmal idiopathic atrial fibrillation. American heart journal. 1998;135(5):733-38.

8. Pérez-Riera AR, de Abreu LC, Barbosa-Barros R, Grindler J, Fernandes-Cardoso A, Baranchuk A. P-wave dispersion: an update. Indian pacing and electrophysiology journal. 2016;16(4):126-33.

9. Yazici M, Ozdemir K, Altunkeser BB, Kayrak M, Duzenli MA, Vatankulu MA, Soylu A, Ulgen MS. The effect of diabetes mellitus on the P-wave dispersion. Circulation Journal. 2007;71(6):880-83.

10. Aytemir K, ÖZER N, Atalar E, Sade E, AKSÖYEK S, ÖVÜNÇ K, Oto A, ÖZMEN F, Kes S. P wave dispersion on 12 lead electrocardiography in patients with paroxysmal atrial fibrillation. Pacing and Clinical Electrophysiology. 2000;23(7):1109-12.

11. Özmen F, Atalar E, Aytemir K, Özer N, Aç11 T, Övünç K, Aksöyek S, Kes S. Effect of balloon-induced acute ischaemia on $\mathrm{P}$ wave dispersion during percutaneous transluminal coronary angioplasty. EP Europace. 2001;3(4):299-303.

12. Aahin BD, Y11d1r1m E, Ipek E, Cengiz M, Aslan K, Poyraz E, Demirelli S, Bayantemur M, Ermis E, Ciftci C. The Relationship between P \& QT Dispersions and Presence \& Severity of Stable Coronary Artery Disease. Korean circulation journal. 2016;46(4):522-29.

13. Akin F, Firatli I, Katkat F, Gurmen T, Ayca B, Kalyoncuoglu M, Abaci O, Sari M, Ersanli M, Kucukoglu S, Yigit Z. P-wave dispersion and its relationship with the severity of the disease in patients with stable coronary artery disease. Northern clinics of Istanbul. 2014;1(2):65.

14. Yilmaz R, Demirbag R. P-wave dispersion in patients with stable coronary artery disease and its relationship with severity of the disease. Journal of electrocardiology. 2005;38(3): 279-84. 